\title{
ANALISIS SISTEM PENCEGAHAN BAHAYA KEBAKARAN PADA GEDUNG MUSEUM PENERANGAN DI KAWASAN WISATA TAMAN MINI INDONESIA INDAH
}

\author{
ANALYSIS OF FIRE HAZARD PREVENTION SYSTEMS \\ IN THE LIGHTING MUSEUM BUILDING IN TAMAN MINI \\ INDONESIA TOURISM AREA
}

\author{
Nafsan Upara ${ }^{1)}$, PS.Dyah Prinajati ${ }^{2)}$ \\ ${ }^{1)}$ Jurusan Teknik Mesin, Fakultas Teknik, Universitas Pancasila \\ ${ }^{2)}$ Jurusan Teknik Lingkungan, Fakultas Teknik, Universitas Sahid Jakarta \\ Email: uparanafsan@gmail.com \\ Email: iinsoekandar@gmail.com
}

\begin{abstract}
Museum Penerangan is one of tourist attractions which is visited by tourist to increase the knowledge of lighting development in Indonesia. Museum Penerangan has fire protection system, but the reliability of building safety system of potential fire hazard needs to be known. This research is conducted to acknowledge Museum Penerangan reliability of building safety system. Reliability variables used in this research are the completeness of treads, safety tools, active fire protective systems, and passive fire protective systems. The research obtains the value of reliability of Museum Penerangan building safety system for potential fire hazard is 68,9895, which means Moderate. This value is inadequate to minimum requirements of reliability of building safety system that has value of 80 or Good. This is due to safety tools component's variable that has value of 58,57. It is recommended for the Museum Penerangan management to increase or develop the safety tools' components that have been lacking of function so that the building could have a better reliability level of potential fire hazard.
\end{abstract}

Keywords: Tours, museum, potential fire hazard, reliability of building safety system, fire protective systems

\section{Pendahuluan}

Bangunan gedung dapat berfungsi sebagai kantor, pabrik, workshop, tempat pembangkit listrik, tempat dimana mesin mesin beroperasi, mall, pasar, rumah sakit dan lain-lainya. Khusus untuk Museum Penerangan terdapat di Taman Mini Indonesia Indah yang merupakan tempat pariwisata bukan hanya untuk wisatan dari Jakarta saja tetapi juga dari pulau Jawa, luar pulau jawa bahkan manca Negara. Gedung Meseum Penerangan dapat di jadikan salah satu pilihan wisata edukasi yang menawarkan informasi dan pengembangan wawasan terkait sejarah penerangan yang sangat berperan dalam memperjuangan kemerdekaan Indonesia. Museum penerangan memiliki koleksi-koleksi penting dan bersejarah yang di jaga dengan baik diantaranya: kamera perekam pelantikan presiden RI, Jenderal Soeharto (1971), Alat perekam blank (piringan hitam) yang digunakan oleh RRI sejak tahun 1958, dan Radio Oemoem, 1940 bermerk Philips (Belanda) digunakan pada masa kependudukan Jepang (1942-

1945) dimana semua radio memiliki penduduk disegel, dan hanya radiao oemoem saja yang boleh didengarkan. Radio ini dipasang di lokasi yang strategis walau hanya 
dapat mendengarkan siaran sentral pemerintah Jepang, namun pada akhirnya ikut mengumandangkan proklamasi kemerdekaan RI.

Karena Gedung Meseum Penerangan terdapat banyak kegiatan dan melibatkan banyak manusia tentu akan yang menjadi perhatian adalah terjaminnya keamanan dan keselamatan dari potensi-potensi bahaya yang ada. Bahaya potensi Kebakaran yang timbul harus menjadi perhatian khusus pengelola kawasan wisata. Bahaya kebakaran bisa berasal dari aliran arus listrik, puntung rokok, petir, dan lain- lainnya yang berpotensi menimbulkan kebakaran kapan saja sehingga membahayakan para penujunjung terutama pada saat menggunakan wahana tersebut. Tempat wisata berada indoor maupun outdoor sehingga bahaya kebakaran dapat sebagai ancaman yang menggangu kegiatan berwisata dan hilangnya keindahan tempat wisata tersebut.

\section{Landasan Teori}

Kebakaran adalah api yang tidak terkontrol (uncontrol fire) menimbulkan kerugian [1].Terciptanya api karena adanya tiga unsur meliputi udara (oksigen), bahan bakar, dan sumber panas. Ketiga unsur ini harus ada dalam satu tempat dan pada suatu waktu bersamaan maka tercipta api, jika tidak ada salah satu dari tiga unsur tersebut, maka api tidak akan timbul dan kebakaran tidak terjadi.Untuk mengetahui keandalan sistem keselamatan bangunan (KSKB) terhadap bahaya kebakaran perlu dilakukan penilaian. Menurut Erry.dkk [2] parameter penilaian keandalan sistem keselamatan bangunan (SKSB) terhadap kebakaran adalah :

(1) Kelengkaan tapak dengan bobot $25 \%$

(2) Sarana penyelamatan dengan bobot $25 \%$

(3) Sistem Proteksi Aktif dengan bobot 24\%

(4) Sistem Proteksi Pasif dengan bobot 26\%

Untuk mendapatkan nilai keandalan, maka terlebih dahulu dilakukan penilaian terhadap komponen parameter yang mempengaruhi KSKB.

Adapun komponen penilaian pada parameter kelangkapan tapak adalah:

a. Sumber air

b. Jalan lingkungan

c. Jarak antara bangunan

d. Hidran halaman

Komponen penilaian untuk sarana penyelamatan adalah:
a. Jalan keluar
b. Konstruksi jalan keluar
c. Landasan helikopter

Komponen penilaian untuk sistem proteksi aktif adalah:
a. Deteksi dan alarm
b. Siemes Conection
c. APAR
d. Hidran gedung
e. Springler
f. Sistem pemadam luapan
g. Pengendalian asap
h. Deteksi asap
i. Pembuangan asap
j. Lift kebakaran
k. Cahaya darurat
1. Listrik darurat 
m. Ruang pengendalian operasi

Sedangkan komponen sistem proteksi pasif adalah:
a. Ketahanan struktur api bangunan
b. Kompartemenisasi
c. Perlindungan kebakaran

Nilai keandalan yang disyaratkan [2] adalah :

a. Nilai keandalan setiap individu parameter

b. Nilai kumulatif parameter keandalan:

1) Baik (B) : Nilai $>80-100$

2) Cukup (C) : Nilai $60-80$

3) Kurang (K) : Nilai $<60$

Nilai kumulatif parameter KSKB minimum adalah 80 .

\section{Metodologi}

Penelitan yang dilakukan ini termasuk jenis penelitian observasional deskriptif. Melakukan observasi mengenai Keandalan Sistem Keselamatan Bangunan (KSKB) bahaya kebakaran gedung Museum Penerangan Taman Mini Indonesia Indah. Observasi ini mengacu kepada pedoman dan pengamatan teknis sistem proteksi kebakaran gedung baik peraturan pemerintah atau Standar Nasional Indonesia (SNI). Penelitian ini akan dilaksanakan di gedung Museum Penerangan, yang beralamat Jl. Pintu II Taman Mini Indonesia Indah Pondok Gede Jakarta Timur.

\subsection{Teknik Pengambilan Data}

a. Studi pustaka, yaitu mencari referensi dan literature yang terkait dengan sistem manajemen proteksi kebakaran terkhusus bangunan gedung yang akan menjadi data pelengkap yang menguatkan suatu data yang diperoleh dilapangan dan sebagai pembanding dengan data yang ada.

b. Studi lapangan, dilakukan untuk melihat langsung penerapan proteksi kebakaran pada Museum Penerangna dengan menggunakan check-list data-data terkumpul dan kemudian diolah dan dianalisis, melalui :

1) Wawancara, yaitu metode pengambilan data primer secara lisan. Wawancara yang dilakukan untuk mendapatkan penjelasan dan klarifikasi atas permasalahanpermasalahan teknis yang terjadi di lapangan dengan menanyakan langsung kepada pihak yang terkait pengelolaan gedung.

2) Pengambilan data, yaitu pengumpulan data primer dan sekunder dari departemen terkait yang berhubungan dengan aspek yang sedang dikaji sebagai data penunjang dalam pembahasan penelitian ini.

\subsection{Rancangan lembar pengamatan}

Rancangan lembar pengamatan (check list) yang akan dipakai untuk pengumpulan data dan pengamatan langsung di lapangan berisi semua parameter dan komponennya untuk penelitian ini adalah :
a. Kelangkapan tapak
b. Sarana penyelamatan
c. Sistem proteksi aktif
d. Sistem proteksi pasif80 


\section{Pengolahan Data}

\subsection{Identifikasi Bahaya Kebakaran}

Dari data yang diperoleh dilakukan identifikasi kemungkinan terjadi kebakaran pada Museum Penerangan Taman Mini Indonesia Indah disebabkan oleh:
a. aliran listrik,
b. petir, dan
c. api yang dihasilkan oleh puntung rokok pengunjung

\subsection{Keandalan Sistem Keselamatan Bangunan}

Untuk Keandalan Sistem Keselamatan Bangunan (KSKB) maka data-data yang didapati dilakukan pengolahan, cara pengolahan data tiap parameter dan komponennya mengacu kepada landasan pada pedoman teknis pemeriksaan keselamatan kebakaran gedung yang dikeluarkan oleh PUSLITBANG Perumahan dan Pemukiman [2], yaitu:

a. Menghitung nilai keandalan kelengkapan tapak Penilaian parameter dan komponen kelengkapan tapak diperlihatkan pada Tabel 1.

Tabel 1. Penilaian kelengkapan tapak

\begin{tabular}{llccccc}
\hline No & \multicolumn{1}{c}{ Komponen } & Keandalan & Hasil Penilaian & $\begin{array}{c}\text { Bobot } \\
(\boldsymbol{\%})\end{array}$ & Nilai & $\begin{array}{c}\text { Jumlah } \\
\text { Nilai }\end{array}$ \\
\hline 1 & Sumber air & B & 100 & 27 & 27 & 27 \\
2 & Jalan lingkungan & B & 100 & 25 & 25 & 25 \\
3 & Jarak antara bangunan & B & 100 & 23 & 23 & 23 \\
4 & Hidran halaman & C & 75 & 25 & 18,75 & 18,75 \\
\hline & Nilai Total & & & & 93,75 \\
\hline & Nilai parameter kelengkapan tapak & & 25 & & 23,4375 \\
\hline
\end{tabular}

b. Menghitung nilai keandalan sarana penyelamatan. Penilaian parameter dan komponen sarana penyelamatan diperlihatkan pada Tabel 2.

Tabel 2. Penilaian sarana penyelamatan (bobot: 25\%)

\begin{tabular}{llccccc}
\hline No & \multicolumn{1}{c}{ Komponen } & Keandalan & Hasil Penilaian & $\begin{array}{c}\text { Bobot } \\
(\%)\end{array}$ & Nilai & $\begin{array}{c}\text { Jumlah } \\
\text { Nilai }\end{array}$ \\
\hline 1 & Jalan keluar & $\mathrm{C}$ & 75 & 38 & 28,5 & 28,5 \\
2 & Konstruksi jalan keluar & $\mathrm{B}$ & 85 & 35 & 29,75 & 29,75 \\
3 & Landasan helikopter & $\mathrm{K}$ & 0 & 27 & 0 & 0 \\
\hline \multicolumn{2}{l}{ Nilai Total } & & & & & 58,75 \\
\hline & Nilai parameter sarana penyelamatan & & 25 & & 14,562 \\
\hline
\end{tabular}

c. Menghitung nilai keandalan proteksi aktif Penilaian parameter dan komponen proteksi aktif diperlihatkan pada Tabel 3.

Tabel 3. Penilaian proteksi aktif

\begin{tabular}{llccccc}
\hline No & \multicolumn{1}{c}{ Komponen } & Keandalan & $\begin{array}{c}\text { Hasil } \\
\text { Penilaian }\end{array}$ & $\begin{array}{c}\text { Bobot } \\
(\boldsymbol{\%})\end{array}$ & Nilai & $\begin{array}{c}\text { Jumlah } \\
\text { Nilai }\end{array}$ \\
\hline 1 & Deteksi dan alarm & $\mathrm{C}$ & 75 & 8 & 6 & 6 \\
2 & Slemes connection & $\mathrm{B}$ & 82 & 8 & 6,56 & 6,56 \\
3 & ASPAR & $\mathrm{K}$ & 30 & 8 & 2,4 & 2,4 \\
4 & Hidran gedung & $\mathrm{K}$ & 50 & 8 & 4,0 & 4,0 \\
5 & Springkler & $\mathrm{K}$ & 0 & 8 & 0 & 0
\end{tabular}




\begin{tabular}{llccccc}
\hline No & \multicolumn{1}{c}{ Komponen } & Keandalan & $\begin{array}{c}\text { Hasil } \\
\text { Penilaian }\end{array}$ & $\begin{array}{c}\text { Bobot } \\
(\boldsymbol{\%})\end{array}$ & $\begin{array}{c}\text { Nilai } \\
\text { Jumlah } \\
\text { Nilai }\end{array}$ \\
\hline 6 & Sistem pemadam luapan & $\mathrm{C}$ & 70 & 7 & 4,9 & 4,9 \\
7 & Pengendalian asap & $\mathrm{K}$ & 60 & 8 & 4,8 & 4,8 \\
8 & Deteksi asap & $\mathrm{C}$ & 70 & 8 & 5,6 & 5,6 \\
9 & Pembuangan asap & $\mathrm{C}$ & 70 & 7 & 4,9 & 4,9 \\
10 & Lift kebakaran & $\mathrm{K}$ & 0 & 7 & 0 & 0 \\
11 & Cahaya darurat & $\mathrm{K}$ & 0 & 8 & 0 & 0 \\
12 & Listrik darurat & $\mathrm{K}$ & 0 & 8 & 0 & 0 \\
13 & Ruang pengendalian operasi & $\mathrm{C}$ & 70 & 7 & 4,9 & 4,9 \\
\hline \multicolumn{2}{l}{ Nilai Total } & & & & & 44,06 \\
\hline \multicolumn{2}{l}{ Nilai parameter proteksi aktif } & & 24 & & 10,574 \\
\hline
\end{tabular}

d. Menghitung nilai keandalan proteksi pasif Penialain parameter dan komponen proteksi pasif diperlihatkan pada Tabel 4.

Tabel 4. Penilaian proteksi pasif

\begin{tabular}{llccccc}
\hline No & \multicolumn{1}{c}{ Komponen } & Keandalan & Hasil Penilaian & $\begin{array}{c}\text { Bobot } \\
(\%)\end{array}$ & Nilai & $\begin{array}{c}\text { Jumlah } \\
\text { Nilai }\end{array}$ \\
\hline 1 & Ketahanan api struktur & B & 83 & 36 & 29,88 & 29,88 \\
& bangunan & C & 75 & 32 & 24 & 24 \\
3 & Kompartemenisasi & B & 77 & 32 & 24,64 & 24,64 \\
\hline & Perlindungan kebakaran & Nilai Total & & & & 78,52 \\
\hline & Nilai parameter proteksi pasif & & & & 20,416 \\
\hline
\end{tabular}

\section{Pembahasan}

Dari pengumpulan dan pengolahan data, dapat disampaikan analisis sebagai berikut:

a. Museum Perenangan memiliki asset sejarah bangsa Indonesia khusus peralatan dan dokumen sejarah penerangan di Indonesia yang perlu diperliharan dan di lindungi dengan baik.

b. Dari hasil identifikasi bahaya, bahwa kebakaran bisa terjadi di Gedung Museum Penerangan dapat disebab oleh aliran listrik, petir, dan api yang dihasilkan oleh puntung rokok pengunjung.

c. Hasil pengolahan data terhadap penilaian tingkat Keandalan Sistem Keselamatan Bagunan (KSKB) dari tabel 1 sampai dengan tabel 4, secara ringkas diperlihatkan pada Tabel 5.

Tabel 5. Total penilaian tingkat KSKB

\begin{tabular}{llccc}
\hline No & Parameter KSKB & Nilai & Bobot (\%) & Jumlah Nilai \\
\hline 1 & Kelengkapan tapak & 93,75 & 25 & 23,4375 \\
2 & Sarana penyelematan & 58,75 & 25 & 14,562 \\
3 & Sistem proteksi aktif & 44,06 & 24 & 10,574 \\
4 & Sistem proteksi pasif & 78,52 & 26 & 21,416 \\
\hline & & & 68,9895 \\
\hline
\end{tabular}

Dari tabel.5 terlihat bahwa tingkat keandalan sistem keselamatan bangunan gedung Museum Penerangan terhadap bahaya kebakaran nilainya 68,9895 dengan katergori keandalan penilaian cukup (C). Namun, untuk menjamin keselamatan dan kenyamanan gedung secara keseluruhan, nilai keandalan sistem keselamatan bangunan tidaklah boleh kurang dari 80 atau baik (B). Untuk itu, maka nilai 
minimum untuk tiap Parameter harus dilakukan perbaikan untuk mendapatkan nilai 80 (Baik).

d. Parameter dan komponen Tingkat Keandalan Sistem Keselamatan Bangunan Museum Penerangan yang menjadi perhatian dalam perbaikan adalah:

1) Sarana penyelamatan karena nilai KSKB adalah 58,75

2) Sistem Proteksi Aktif dengan nilai KSKB adalah 44,06

3) Sistem Proteksi Pasif dengan nilai KSKB 78,52

\section{Kesimpulan dan Saran}

\subsection{Kesimpulan}

a. Secara keseruluhan Keandalan Sistem Keselamatan Bangunan (KSKB) pada gedung Museum Penerangan memiliki nilai 68,9895 yang berarti cukup (C) yaitu komponen proteksi kebakaran terpasang dan ada yang tidak terpasang dan sebagaian instalasi yang tidak sesuai dengan persyaratan.

b. Secara individu komponen penilaian Sub KSKB pada gedung Museum Penerangan, adalah sebagai berikut :

1) Parameter KSKB, kelengkapan tapak memiliki nilai 93,75 yang bararti baik (B)

2) Parameter KSKB, sarana penyelamatan memiliki nilai 58,75 yang berarti kurang (K)

3) Parameter KSKB, sistem proteksi aktif memiliki nilai 44,04 yang berarti kurang (K)

4) Parameter KSKB, sistem proteksi pasif memiliki nilai 78,52 yang berarti cukup (C).

\subsection{Saran}

1. Untuk parameter dan komponen KSKB yang tidak memenuhi persyaratan disarankan sebagai berikut:

a. Komponen Sarana Penyelamatan

Komponen sarana penyelamatan memiliki nilai kurang (K) yaitu 58,75. Disarankan:

1) Jalan keluar harusnya memiliki 2 jalan keluar dengan tinggi efektif 2,5 meter dengan lebar jalan keluar 2 meter. Jika lebar jalan keluar kurang dari 2 meter atau hanya 1,5 meter dan

2) Jalan keluar terhalangi oleh tumpukan barang-barang. Untuk itu, barangbarang yang menghalangi jalan keluar harus dipindahan.

3) Pada gedung Museum Penerangan tidak memiliki landasan helikopter kerena tinggi bangunan hanya 24 meter sehingga direkomendasikan dibuat Master point pengganti landasan Helikopter.

b. Komponen Proteksi Aktif

Gedung museum Penerangan memiliki proteksi kebakaran aktfif yang kurang (K) yaitu 44,06 dari kriteria persyaratan yang baik, disarankan :

1) Dipasang springkler,

2) Diadakan lift kebakaran,

3) Dipasang lampu untuk cahaya darurat,

4) Diadakan Genset darura untuk candangan jika listrik dari PLN padam.

5) Perbaiki hidran yang tidak berfungsi

6) Secara berkala dilakukan pengetesan peralatan proteksi kebakaran yang ada.

7) Secara berkala dilakukan perawatan terhadap peralatan proteksi yang ada. 
c. Komponen Proteksi Pasif

Komponen proteksi pasif nilainya cukup (C) 78,52 perbaikan yang diusulkan terhadap komponen Ketahanan api struktur bangunan Kompartemenisasi, dan Perlindungan kebakaran, sehingga rekomendasi yang diusulkan adalah :

1) Perawatan dan perbaikan berkala

2) Penyetelan/perbaikan komponen yang rusak

2. Untuk parameter dan komponen KSKB yang memenuhi persyaratan yaitu parameter Kelengkapan Tapak disarankan sebagai berikut:

a. Pemeriksaan secara berkala

b. Perawatan/pemeliharaan berkala

c. Perawatan dan perbaikan berkala

3. Untuk Pedoman Teknis Pemeriksaan Keselamatan Kebakaran Bangunan Gedung, saran perbaikan adalah:

a. Pada penilaian per sub komponen KSKB tidak akan terlihat nilai-nilai yang sangat kurang atau bahkan tidak ada sub komponennya pada gedung, karena nilai sub komponen KSKB di rata-ratakan.

b. Pada contoh kasus misalnya pada sub komponen KSKB sarana penyelamatan yaitu landasan helikopter dengan salah satu kriteria penilaiannya adalah hanya pada bangunan tinggi minimal 60 meter sedangkan pada gedung tertentu yang tinggi tidak sampai 60 meter akan memiliki nilai nol (O) namun harus tetap masuk penilaian secara keseluruhan sub komponen KSKB sarana penyelamatan.

\section{Daftar Pustaka}

Schroll, R. Craig, 2002, Industrial fire protection handbook, 2nd ed CRC Press, London

Saptaria, Erry et al. 2005. Pedoman Teknis Pemeriksaan Keselamatan Kebakaran Bangunan Gedung. Bandung. Puslitbang Pemukiman, Badan Penelitian dan Pengembangan PU, Departemen Pekerjaan Umum.

Departemen Pekerjaan Umum, 2008. Persyaratan Teknis Sistem Proteksi Kebakaran pada Bangunan Gedung dan Lingkungan. Peraturan Menteri Pekerjaan Umum No. 26/PRT/M/2008, 30 Desember 2008

Departemen Pekerjaan Umum. 2009. Pedoman Manajemen Proteksi Kebakaran di Perkotaan. Peraturan Menteri Pekerjaan Umum No. 20/PRT/M/2009

Heni, Yusri. 2011. Improving Our Safety Culture. Jakarta: Gramedia Pustaka Utama.

Ismayanti. 2010. Pengantar Pariwisata. Jakarta: Grasindo.

Keputusan Menteri Tenaga Kerja Republik Indonesia No. Kep 189/MEN/1999/ tentang Unit Penanggulangan Kebakaran di Tempat Kerja.

Napitupulu, Painim, Dulbert Biatna dan Komalasari Dewi. 2015. Evaluasi Sistem Proteksi Kebakaran Perusahaan. Bandung: Alumni.

Napitupulu, Painim dan Dulbert Biatna. 2015. Sistem Proteksi Kebakaran Kawasan Pemungkinan dan Perkantoran. Bandung. Alumni.

Peraturan Menteri Tenaga Kerja dan Transmigrasi No: PER.04/MEN/1980 tentang Syaratsyarat Pemasangan dan Pemeliharaan Alat Pemadam Api Ringan.

Ramli, Soehatman. 2010. Sistem Manajemen Keselamtan dan Kesehatan Kerja OHSAS 18001. Jakarta: Dian Rakya 
Ramli, Soehatman. 2010. Manajemen Kebakaran. Jakarta: Dian Rakyat.

Suma'mur P.K, 1981. Keselamtan Kerja dan Pencegahaan Kecelakaan. Jakarta: Gunung Agung.

Soedarto, Gatot.1984. Pencegahan dan Penanggulangan Bahaya Kebakaran. Grafindo tama. Jakarta.

SNI (03-1735-2000) tentang Tata Cara Perencanaan Akses Bangunan dan Akses Lingkungan untuk Pencegahan Bahaya Kebakaran pada Bangunan Gedung. 